\title{
O Atendimento da Crise Psicogênica nos Prontos-Socorros
}

\author{
Psychogenic Seizure Care in Accident and \\ Emergency Units
}

Thiago Paes de Barros De Luccial Danna Paes de Barros De Luccial

\section{PALAVRAS-CHAVE \\ - Serviços Médicos de Emergência. \\ - Educação Médica. \\ - Aspectos Psicogênicos. \\ - Transtorno Conversivo.}

\section{KEYWORDS}

- Emergency Medical Services.

- Medical Education.

- Psychogenic Aspects.

- Conversion Disorder.

Recebido em: 03/08/2010

Reencaminhado em: 01/02/2011

Reencaminhado em: 28/04/2011

Aprovado em: 04/05/2011

REVISTA BRASILEIRA DE EDUCAÇÃO MÉDICA

\section{RESUMO}

Este artigo analisa um aspecto da clínica médica e a rotina de acolhimento de doenças psicogênicas neste campo. A partir do fragmento de um caso de atendimento médico em pronto-socorro, observou-se um desmerecimento a pacientes com manifestações histéricas com somatização, consideradas pela equipe da instituição, ironicamente, como "emergências emocionais" ou "pitis". Tal comportamento reflete um problema clássico da deficiência de conhecimento sobre a medicina psicossocial, que se torna paradigmático nestes casos, onde há uma linha tênue entre o psíquico e o corporal. Para entender essa dinâmica, acreditamos que seja necessária uma incursão no contexto histórico do privilégio do diagnóstico racional, do discurso científico e suas influências no ensino médico contemporâneo.

\section{ABSTRACT}

This article investigates one part of medical practice and the routine of receiving psychogenic patients in that area. In one case at an accident and emergency unit, patients suffering hysterical somatization were pejoratively considered as "emotional emergencies" or "pitis" (a slang term for hysterical fit) by the health professionals, who questioned the need for medical care. Such behaviour reflects a classic problem of insufficient knowledge of psychosocial medicine, which forms the paradigmatic basis in such cases, where there is a fine line between the mental and the corporal. To understand this dynamic, we believe an investigation is required into the historical context of the centre stage given to rational diagnosis, scientific discourse and their influences on contemporary medical education. 


\section{INTRODUÇÃO}

As chamadas emergências psiquiátricas fazem parte das emergências clínicas gerais que chegam diariamente aos prontos-socorros. Tais emergências abrangem situações de risco para o paciente ou outrem, proporcionadas por crise psicológica ou transtorno psiquiátrico, e, muitas vezes, são entendidas como irrelevantes. Os próprios livros de emergências médicas reconhecem que "o paciente em uma situação de emergência psiquiátrica é vítima de forte preconceito por parte da equipe e dos demais pacientes do serviço" ${ }^{\prime 1}$ (p. 1.063).

É preciso lembrar que os níveis de atendimento à saúde ditos secundários e terciários, que abrangem hospitais de médio e grande porte, sofrem muito com a superlotação dos serviços. A cultura hospitalocêntrica que leva multidões aos hospitais, muitas vezes por queixas que poderiam ser abordadas na atenção primária (por exemplo, nas unidades básicas de saúde), é um problema sério quando se pensa no que seria um atendimento "de qualidade" em um pronto-socorro. Tal cultura teve sua origem no início do século $X X$, sendo importante ressaltar Abraham Flexner ${ }^{2}$, que propôs maior envolvimento entre hospitais e universidades, repercutindo numa demanda por conhecimentos cada vez mais específicos e fragmentados. Assim, reduziram-se os valores antes vigentes, como a relação médico-paciente e a escuta de implicações psicossociais do adoecimento $^{3}$ (p. 492).

A partir da década de 1950, novas críticas questionam a eficácia da primazia da racionalidade no discurso médico, inaugurando um enorme campo de discussão que nos remete, por exemplo, às análises de Balint sobre a psicologia médica e a relação médico-paciente. O autor mostrou a importância de um "diagnóstico que não se limite à compreensão de todos os sinais e sintomas físicos, mas que também tente avaliar a pertinência dos assim chamados sintomas "neuróticos'”. Seria aconselhável que o médico aspire a "um diagnóstico mais amplo e profundo"4 (p. 43). O mesmo autor ressalta o papel da psicoterapia nas relações médicas e aponta duas posições conflitantes: os entusiastas da psicoterapia afirmam que ela é um dos mais importantes métodos terapêuticos disponíveis; já seus inimigos afirmam que tal prática não tem justificação científica $^{5}$ (p. 9). Em meio aos defensores de práticas terapêuticas mais "psíquicas" e mais "biologizantes", os médicos teriam dificuldade de identificação com tais vertentes. Nesse contexto, o autor coloca em questão o papel da psicoterapia na medicina, tratando de aspectos da prática clínica e do ensino de graduação em Medicina.

A reforma sanitária brasileira marcou um importante momento histórico ao buscar uma transformação das concepções de adoecimento então vigentes, articulando a noção desenvol- vida pela Organização Mundial de Saúde (OMS), que atenta para um conceito amplificado de saúde como um bem-estar tanto físico quanto mental e, portanto, não considera a saúde somente como ausência de doença. Então, implementou-se o Sistema Único de Saúde brasileiro (SUS), a partir da Constituição federal de 1988, que legitimou o acesso universal à saúde por toda a população, trazendo o conceito de saúde como direito e dever do Estado. Juan Gérvas ${ }^{6}$, ao comentar tal papel do Estado na saúde e na proteção social, diz que o Estado não teria o poder de garantir "saúde" para a população, mas, sim, o poder de garantir certa política de cuidado.

Algumas políticas governamentais foram criadas para se assimilar este novo modo de pensar a saúde, tanto na prática do trabalho quando na área educacional. Dentre elas, destaca-se o projeto de humanização (humanizaSUS), instituído pelo Ministério da Saúde e implementado em 2004 em âmbito nacional, e a proposta das Diretrizes Curriculares Nacionais de 2001, que preconiza para a graduação em Medicina uma formação humanista, generalista, reflexiva e crítica, que desenvolva no estudante valores e atitudes em prol da cidadania.

Contudo, apesar do grande reconhecimento do SUS e das melhorias do atendimento à população, observa-se que a desconstrução do modelo médico vigente, em sua prática tanto clínica quanto educacional, oferece resistência. Ao analisarmos relatos da prática hospitalar, temos indícios de que tais políticas acabam exercendo baixa influência no sistema de saúde como um todo. A que isto se deve? Por que a prática clínica dessubjetivada se mantém, mesmo com tantas iniciativas governamentais na saúde e educação públicas? Que outras dimensões a questão pode trazer para podermos pensar sobre isto?

Adiantamos a hipótese de que a modernização e o desenvolvimento tecnológico exigem cada vez mais o aprimoramento profissional e as especializações para o domínio da técnica. A especialização, por sua vez, é importante aos profissionais no processo de identidade individual, onde se prima pela excelência e pelo desempenho, o que gera prestígio profissional. Esta lógica se firma durante a formação universitária e se reproduz de forma hierárquica nas instituições de saúde, garantindo a primazia do discurso médico científico. Contudo, as dificuldades na recuperação da dimensão sociológica e integralista da medicina não serão superadas somente com mudanças políticas ou pedagógicas, sem uma reavaliação dos valores que permeiam o exercício médico. Demandas excessivas de conhecimento sobre o corpo físico impedem uma abertura a outros tipos de conhecimento sobre o homem.

Imbricados num contexto socioeconômico que funciona majoritariamente para manter a lógica da satisfação e afastar 
a angústia, os estudantes de Medicina se veem "obrigados" a corresponder às expectativas de ótimo desempenho frente à grande demanda de atendimento à população e abandonam antigas concepções sobre a importância da prática médica integralista. $\mathrm{O}$ abandono é justificado pela realidade, que seria incompatível com esta concepção supostamente "romântica" do exercício desta medicina, mas se escondem nesta justificativa outras implicações subjetivas dos profissionais que contribuem para o afastamento dos casos que envolvem questões emocionais. Buscaremos, portanto, abordar a problemática em suas dimensões política, educacional e psicológica a fim de delinear um diagnóstico mais amplo sobre a dessubjetivação da prática médica.

O caso a seguir serviu-nos de amostra sobre a prática das equipes de saúde nos prontos-socorros e nos apresenta a tarefa de pensar nas articulações deste tipo de situação com a formação médica e a reprodução do discurso científico nas instituições e na prática de atendimento.

A partir da observação da rotina em um pronto-socorro (PS) de um hospital de nível secundário de São Paulo, focaremos nossa análise no atendimento dos casos de crise psicogênica que a equipe do local prefere classificar, ironicamente, como "emergências emocionais" ou "pitis". Para ilustrar melhor nossa análise, exporemos fragmentos de um caso fictício baseado na vivência prática de um pronto-socorro de um hospital onde se observa um episódio histérico manifesto por meio de dor somática e também todo o entorno da situação do atendimento comumente presenciado nesse contexto institucional.

\section{O CASO}

Uma jovem chega ao pronto-socorro desacordada, trazida pelo namorado numa cadeira de rodas. Um cirurgião faz o primeiro atendimento e, após um exame rápido e algumas perguntas, logo passa o caso a um residente da clínica médica, dizendo: 'tem uma moça ali, em Glasgow 15 (pontuação máxima para o nível de consciência), que eu acho que é pra vocês, deve ser piti". O residente pergunta ao casal o que aconteceu, e o namorado relata que, após terem uma discussão, ela desmaiou. Depois de descartar hipoglicemia, hipotensão ou quaisquer alterações orgânicas mais graves, o clínico oferece um copo d'água e um pouco de soro fisiológico para beber (já que ela pedira sal). Ela ameaça vomitar algumas vezes, demora para conseguir dar alguns goles, mas vai melhorando um pouco. Quando começa a falar mais, diz que sua visão estava turva e a cabeça formigava. O médico prescreve, então, um diazepam via oral. Em cerca de meia hora ela se recupera totalmente e sai andando em bom estado geral. A recepcionista do PS comenta com o residente: 'ficou boa rápido a moça, não é?' (com certo riso sarcástico).
O termo "piti" vem de "pitiatismo", designado por Joseph Babinski (1857-1932) como distúrbios secundários da histeria rigorosamente subordinados aos ditos primários ${ }^{7}$. De acordo com Babinski, o sujeito então é capaz de provocar um exagero nos sintomas através da sugestão, como, por exemplo, reagir intensamente a um discurso provocativo. Assim, casos como esses são tidos como desimportantes pelas equipes de saúde, por se tratar de uma suposta crise histérica baseada numa reação exacerbada com algum propósito secundário. Trata-se de uma interpretação reducionista da explicação de Babinski, no sentido em que desconsidera a determinação de um distúrbio histérico primário.

Desde o final do século XIX, época em que Sigmund Freud se interessou em pesquisar a histeria, pacientes que procuravam por atendimento médico com sintomas aparentemente sem origem orgânica definível já sofriam grande preconceito e, muitas vezes, eram negligenciados. Felizmente, inspirado por Jean Marie Charcot em seu estágio em Paris e por seu mentor Joseph Breuer, Freud desenvolveu o campo de atuação no tratamento das "doenças nervosas", abrindo espaço para uma legitimação do adoecimento psíquico.

A investigação da etiologia destas neuroses revelou a capacidade que nossa mente tem para produzir sintomas físicos em nosso corpo. O então jovem médico observou que os sintomas somáticos das pacientes histéricas - como parestesias, formigamentos, visão turva e vertigem, entre outros - poderiam surgir a partir de um mecanismo psíquico que chamou de conversão, processo no qual uma ideia incompatível com os valores do indivíduo seria recalcada por meio de um mecanismo de defesa operado inconscientemente. Tais pensamentos recalcados seriam originalmente permeados por uma intensa carga emocional. Contudo, o que possivelmente se transformaria em sofrimento mental tem seu afeto dissociado e deslocado, ou seja: a representação ideativa fica inconsciente, enquanto o afeto, agora "desligado" desta mesma representação, acha um caminho físico para sua descarga. A partir disto, o sintoma somático se desenvolve mediante uma série de associações simbólicas intricadas e, na maioria dos casos, traz uma apropriação de sensações orgânicas já experimentadas (complacência somática). Citando Freud: "A lembrança que forma o conteúdo de um ataque histérico é uma lembrança inconsciente, ou, mais corretamente, faz parte do segundo estado da consciência, que está presente, organizado em grau maior ou menor, em toda histeria ${ }^{8 \prime \prime}$. (p. 73)

Com as formulações que obteve a partir da clínica da histeria, Freud pôde também aplicar a teoria do recalque e a noção de inconsciente a outras neuroses, como a fobia e a obsessão, e concluiu que o recalcamento é inerente à constitui- 
ção psíquica de todos nós. Isto ocorre porque, já na infância, renunciamos à satisfação pulsional indiscriminada (perversa e polimorfa), muitas vezes também direcionada aos genitores (paradigma edípico - desejo de um dos genitores e ódio ao outro), para poder usufruir do convívio adequado em sociedade. Assim, realizamos o que a psicanálise entende como recalque originário, ou seja, os meios de satisfação até então praticados não podem mais ser aceitos socialmente e, por intermédio da culpa (pelo desejo e pelo ódio), precisam ser esquecidos, ou recalcados. Para isso, torna-se necessário outro espaço psíquico no qual as lembranças não podem mais ser acessadas, visto que são geradoras de culpa e angústia, e então ocorre uma divisão psíquica tópica: consciente e inconsciente. O problema é que o conteúdo "esquecido" é uma ideia, mas o afeto ligado a esta mesma ideia não pode ser recalcado. Assim, a exigência pulsional nunca cessa e sempre busca novos objetos para investir libidinalmente, nos colocando a intermitente tarefa de busca por satisfação. Dependendo da qualidade da "resolução" que damos ao destino dos afetos livres, podemos deixar margem ao desenvolvimento dos sintomas que acabam servindo, inconscientemente, como via de satisfação pulsional. Quanto maior a incidência do recalque, mais chance damos ao surgimento de neuroses.

A concepção do inconsciente foi revolucionária para a época e avaliada como uma das feridas narcísicas da humanidade ao revelar que, por esse viés, não somos sequer senhores de nós mesmos e que a consciência é a menor parcela de nossa vida psíquica. A cultura tem um papel fundamental na gênese dos quadros histéricos, e a análise destes se presta inclusive a uma crítica social, na medida em que é possível arquitetar as psicopatologias como representantes de um mal-estar na sociedade.

A "pós-modernidade" traz consigo outras formas de manifestação das neuroses nem sempre permeadas pelo mecanismo psicológico de conversão do afeto encontrado na histeria. No caso apresentado, temos notícias de que houve, sim, um mecanismo de conversão, contudo a falta de uma anamnese detalhada nos deixa margem para cogitar outras possibilidades diagnósticas. É importante nos ater um pouco a este quesito a fim de discutir elementos para diferenciar outros tipos de manifestações muito comuns nos prontos-socorros que podem ser consideradas para um diagnóstico diferencial.

A investigação da incidência do sintoma sobre o plano somático vem sensibilizando a psicanálise contemporânea por se diferenciar com cada vez mais frequência da patologia da histeria, na qual o sintoma conta com um processo simbólico de conversão do afeto para o corpo. Diferentemente disto, o que se verifica hoje é o aumento de manifestações nas quais o afeto, independentemente do tipo de neurose, se liga diretamente ao corpo, sem mediação simbólica, tanto pela via do adoecimento, quanto pela via da ação/compulsão. Freud indicou, em alguns momentos de sua obra, que a investigação psicanalítica teria pouco a contribuir no tratamento destas formas rudimentares de "descarga" de afeto que, sem mediação simbólica, não comportariam um sentido a ser desvendado e interpretado: seriam as chamadas neuroses atuais, com as subcategorias da neurastenia e neurose de angústia. Esta última foi reatualizada teoricamente no que hoje se convencionou chamar de síndrome do pânico, com presença de sintomas físicos exacerbados de angústia, como palpitação, sudorese e taquicardia.

Com o aumento de pacientes com a presença de somatizações na contemporaneidade, muitos teóricos pós-freudianos se debruçaram sobre o estudo destes casos, a fim de abarcar a dinâmica desta forma de destinação dos afetos para o soma, que estaria aquém do mecanismo encontrado no recalcamento da conversão histérica. Foi a partir deste cenário que nasceu a psicossomática, com o desafio de tratar estas manifestações que, por serem isentas de mediação simbólica, não assumiriam o estatuto de sintoma para a psicanálise. Mesmo com estas mudanças através do contexto histórico-social, ainda é possível presenciar casos nos quais as formações sintomáticas se assemelham às da histeria clássica da era vitoriana. Contudo, a modernização, os processos de individualização e as mudanças nas relações de gênero e família nos obrigam a investigar novas formas de relação entre sujeito, corpo e mundo.

Michel Joubert, por exemplo, conceituou como "pequena epidemiologia do mal-estar" uma síndrome coletiva de cunho biopsíquico que se apresenta com dores difusas, ansiedade depressão, etc., que atinge milhões de pessoas nas grandes cidades. $\operatorname{Madel}^{9}$ (p. 147), ao citar tal autor, concebe esse "mal-estar" massivo como um fenômeno de natureza sanitária e também cultural. Suas raízes não estariam somente nas condições adversas de trabalho do capitalismo global, mas imbricadas nas vicissitudes recentes da cultura, fruto da realidade socioeconômica vigente.

A partir destas novas configurações sociais, é interessante fazer um breve inventário psicológico sobre as correntes que visam estudar a contemporaneidade das relações intermediadas pelo corpo, que aqui entenderemos por corporeidade. Com isso pretendemos contribuir com alguns elementos para a prática diagnóstica diferencial.

Ao ponderar as diversas lentes para investigar a corporeidade em psicanálise, notamos que existe um intenso debate sobre os limites entre o psíquico e o somático, entre um corpo simbólico e um corpo real, o que nos leva a supor que a ideia de pulsão traz um complexo de elementos e não se reduz so- 
mente a intermediar o mental e o orgânico. Dunker ${ }^{10}$, em breve ensaio sobre a experiência da corporeidade, analisa seis grandes modelos metapsicológicos para entender suas manifestações clínicas: (a) somatização: terminologia utilizada por Franz Alexander que busca uma etiologia indireta das manifestações somáticas que alterariam a economia da angústia polarizada em algum órgão específico; (b) equivalente de angústia: segue o paradigma das neuroses atuais aplicadas ao campo genérico do que Freud chamava de equivalentes de angústia enquanto manifestações motoras ou certas parapraxias (tal modelo influenciou as investigações posteriores da Escola Francesa com Pierre Marti para a psicossomática); (c) conversão histérica: modelo primordial da psicanálise pensado a partir das observações, em pacientes histéricas, de um processo de deslocamento da soma de excitação para uma região histoerógena e simbólica do corpo (complacência somática); (d) inibição: caracteriza-se por uma falta de resposta do órgão (sintoma negativo); (e) hipocondria: remete a um quadro aquém das neuroses, atravessado por uma problemática narcísica e melancólica; (f) formação psicossomática: presente na tradição lacaniana com base nas três estruturas clínicas (neurose, psicose e perversão); busca relacionar as formações psicossomáticas à "intermitente incidência do real", ou seja, algo da ordem da angústia manifesta no corpo.

Portanto, por mais que casos como estes sejam entendidos como uma simulação, não merecem nossa desatenção, pois envolvem de fato um processo corporal e um apelo endereçado a quem o receba. Afinal de contas, se o paciente histérico simula, não sabe por que o está fazendo, e esta é nossa abertura para um diálogo possível.

Voltando ao nosso caso clínico, o que estaria por trás dos sintomas apresentados pela moça que chegou desacordada ao pronto-socorro? Haveria aí algum trauma psíquico, uma lembrança especial subjacente? Seria possível acessar tais elementos mentais singulares, mesmo nesse ambiente conturbado?

Com tal demanda por atendimento nos hospitais, a equipe de emergência deve estar preparada para identificar e triar os pacientes que apresentem problemas de saúde mais graves e urgentes. É neste contexto que esse tipo de emergência médica, que leva ao "âmbito psíquico", muitas vezes é encarado como um empecilho ou mesmo como um fingimento, nomeados pela psiquiatria como transtornos factícios.

\section{O QUE É MELHOR NÃO SABER}

Se fizermos uma equação lógica, chegaremos a uma conclusão prévia de que a demanda por atendimento é grande, e a estrutura das instituições é precária; logo, "priorizemos casos graves". Contudo, o argumento da "falta de tempo, espaço e profissionais" para o atendimento adequado a toda a população acarreta uma "recusa" de casos como o exemplificado acima. Sob certo ponto de vista, tais casos seriam mais complexos por envolverem uma série de articulações psicossociais a serem feitas e, teoricamente, demandarem muito trabalho. Portanto, não justificariam a ocupação da equipe em detrimento de outros casos mais emergenciais. Soa quase como um insulto que casos de histeria apareçam num pronto-socorro.

Pensando freudianamente, sabemos que certos assuntos que nos causam desconforto geram rejeição e podem promover uma intensa defesa contra ideias psíquicas conflitivas a ponto de torná-las inacessíveis à consciência. A teoria deste mecanismo psíquico de defesa foi concebida originalmente para o entendimento da histeria e o funcionamento das neuroses no final do século XIX, mas, como já dito, somos originalmente neuróticos (no que se entende por um indivíduo normal) e dificilmente não teremos algum sintoma ao longo de nossas vidas. Sendo assim, podemos nos questionar se a falta de tempo e a quantidade de profissionais são realmente justificativas para a resistência ao acolhimento das neuroses contemporâneas. Podem ser, em parte, mas tal argumento, muitas vezes, esconde outro motivo mais obscuro a nós mesmos. Entrar em contato com o desamparo e o sofrimento humanos promove uma abertura para que se coloque nossa própria subjetividade em questão. Isto envolve um dispêndio de energia psíquica para lidar com sentimentos de impotência e angústia produzidos frente a nosso frágil ancoramento na vida, nossos medos e conflitos. É disto que não sabemos (e não queremos saber), pois a perda de referências nos deixa à deriva em alto-mar, sem terra à vista, vivência que Freud batizou poeticamente de sentimento oceânico ${ }^{8}$ (p. 215).

"Não saber" e "não ter garantias" de cura e de certeza é desorganizador para a identidade de um médico, que se constitui sob a égide de "ser supostamente aquele que sabe", que dará respostas. É muito mais simples se esquivar, deixar as questões subjetivas para quem se proponha a estudá-las. $\mathrm{O}$ imaginário social nos leva a crer que a prática médica "integralista" é incompatível com a realidade de um contexto socioeconômico que exige velocidade, atualização constante e rapidez diagnóstica. Mas a escuta e o olhar para a totalidade dos sujeitos não têm nada a ver com o tempo, nem com estrutura ou tecnologia, mas, sim, com a maneira como se pensa sobre o adoecimento humano e como se intervém. Abraçar todas essas exigências (e satisfações) da modernização produz cada vez mais formas alienadas de vida. Extingue-se a possibilidade da observação legítima da experiência, na qual o valor é justamente "não saber nada sobre o que se vê" e permitir que o processo reflexivo ajude na busca de novas respostas sobre as verdades estabelecidas. 
Ao analisarmos a dimensão psicológica da prática médica, percebemos que o problema da discriminação/defesa não prejudica somente o paciente, mas interfere diretamente na produção de conhecimentos e indiretamente em sua transmissão: ao evitarmos as situações intricadas (e não querer saber delas), evitamos também a experiência de observação, reflexão e a transformação da compreensão que dela possa surgir.

De acordo com Balint ${ }^{5}$ (p. 11), as próprias emoções dos médicos devem ser muito consideradas nos atendimentos. Ele ressaltava a importância dos possíveis sentimentos de raiva, impaciência, etc., que muitas vezes não podem ser controlados pelos médicos durante uma consulta. Seguindo a linha desse autor, se o médico toma consciência de tais sentimentos e não se deixa levar por eles de forma "inconsciente", pode ocorrer uma comunicação mais efetiva com o paciente.

Pontanto, pensar nos motivos que levam às condutas analisadas na prática emergencial nos leva a uma segunda tarefa: examinar como se dá a produção e transmissão de conhecimento na contemporaneidade e como podemos analisar a influência deste na formação médica universitária e sua prática clínica. Porém, não nos aprofundaremos nessa tarefa neste texto.

\section{TECNOLOGIAS LEVES}

A ciência é responsável apenas por uma parte do corpo clínico, e a outra se deve ao poder da palavra, diz Lacan em 1970. Dentro da clínica - no domínio do pessoal da medicina -, a psicanálise se encarrega daquilo que a ciência abandona e que antigamente era tratado pelas pessoas que tinham a responsabilidade das coisas da fé. Ele ainda escandaliza ao afirmar que "não há ciência do homem porque o homem da ciência não existe, mas apenas seu sujeito"11 (p. 781).

E é neste ponto que pensamos o quanto é importante que a clínica médica trate de sujeitos que podem manifestar seu sofrimento de diferentes maneiras. Quando um profissional de saúde se depara com um caso de sofrimento psíquico, deve entender que este sintoma é a via de comunicação do sujeito. Escutá-lo é legitimar esta manifestação mediante um diálogo que não se permita atravessar pelos discursos da mídia ou da ciência, mas que ouça um sujeito subjetivo, do inconsciente significante e onde a falta-a-ser é traduzida em angústia simbolizada. Desta maneira, cria-se uma demanda para que o próprio sujeito possa procurar um caminho para entender este sintoma e a angústia que nele subjaz, seja por meio de um tratamento ou de qualquer outra maneira em que se autorize a aceitar seu sofrimento como algo genuinamente humano.

Assim, mesmo num ambiente conturbado de um PS, uma boa escuta das queixas do paciente sem julgamentos prévios, visando à identificação de problemas de saúde e possíveis planos terapêuticos mais imediatos, pode fazer diferença na efetividade do atendimento. A tecnologia leve compreende a tecnologia de relações, habilidades para lidar com o encontro de subjetividades e acolher os usuários do serviço, por exemplo, e isto nada tem a ver com o tempo gasto. Somente a mudança nas concepções de doença já conduz a outro olhar sobre o sujeito. Isto nos deixa livres para abarcar a experiência sem precisar dar respostas. $\mathrm{O}$ trabalho na atenção básica à saúde é muito centrado em tal tecnologia, que difere da também necessária tecnologia dura, expressa nos equipamentos e máquinas $^{12}$ (p. 117). A ideia de que "não há tempo" pode ser modificada se a exigência da prática diagnóstica for mais flexível, e a cultura medicamentosa puder dar lugar a outra forma de conceber os cuidados médicos.

\section{CONSIDERAÇÕES FINAIS}

No caso apresentado, temos notícias de que o discurso científico atravessou toda a instituição e não ficou restrito apenas ao corpo médico. Mas este discurso da ciência não deixa lugar algum ao homem. A humanização da saúde preza o respeito e a tolerância, e estes valores acabam sendo distorcidos nas ações sociais. Há de se questionar, então, nossos valores e a maneira racional como são instituídos, e uma maneira possível é dar espaço ao indivíduo que os contesta, conscientemente ou por meio de seus sintomas.

A ciência médica procura entender o homem a partir de um corpo doente, buscando a universalidade de seu funcionamento e uma consequente previsibilidade, remetendo-nos ainda hoje à antiga dicotomia corpo-mente. No entanto, esta racionalização impede que escutemos o sofrimento humano e a sua mensagem, tanto individual, quanto representante de um mal-estar coletivo. Se escutarmos sujeitos como pessoas que simbolizam e se expressam, poderemos abrir espaço para elaborar as experiências e renovar nossas ações.

\section{REFERÊNCIAS}

1. Mansur CG. Neto JG. Emergências psiquiátricas. In: Martins MS, Brandão Neto RA, Scalabrini Neto A, Velasco IT. Emergências clínicas abordagem prática. São Paulo: Manole; 2009.

2. Flexner A. Medical Education in the United States and Canada. New York: Carnegie Foundation for the Advancement of Teaching; 1910.

3. Pagliosa Fl, Da Ros MA. O relatório Flexner: para o bem e para o mal. Rev Bras Educ Med. 2008;32(4):492-9.

4. Balint M. O médico, Seu Paciente e a sua Doença. 2 ed. São Paulo: Athneu; 2005. 
5. Balint M. Psychotherapeutic techniques in medicine. London: Routledge; 2001.

6. Gérvas J. Atención primaria de salud en Europa: tendencias a principio del siglo XXI. Una reflexión con motivo de los XXV años de la Declaración de Alma Ata. Semergen. 2004;30(5):245-57.

7. Ferreira $\mathrm{ABH}$. Novo Dicionário Aurélio. Rio de Janeiro: Nova Fronteira; 2004.

8. Freud S. Obras completas. Mal estar da civilização (1931). Esboços para a comunicação preliminar de 1893. Inibiçoes, Sintomas e Ansiedade (1926). Projeto para uma Psicologia Científica (1895). Aspectos para diferenciar um tipo especial de neurose de angústia - Pulsao e suas vicissitudes (1915). Rio de Janeiro: Imago; 1977.

9. Madel TL. Cultura contemporânea e medicinas alternativas: novos paradigmas em saúde no fim do século $x x$. Physis. 2005;15(Supl.):145-176.

10. Dunker CIL. Elementos para uma Metapsicologia da Corporeidade em Psicanálise. [acesso em 28 abr. 2011]. Disponível em: http://www.fundamentalpsychopathology. org/anais2006/4.66.3.2.htm [Trabalho apresentado no II Congresso Internacional de Psicopatologia Fundamental, (Belém- 2006), na Mesa Redonda Por uma Metapsicologia do Corpo (4.66.1), coordenação de Edilene Queiróz.]
11. Lacan J. O seminário: Livro 17 (1969-70): O avesso da Psicanálise. Rio de Janeiro: Zahar;1966.

12. Zerbetto SR. Pereira MAO. O trabalho do profissional de nível médio de enfermagem nos novos dispositivos de atenção em saúde mental. Re. Latino Am. Enfermagem 2005;13(1):112-7.

\section{CONFLITO DE INTERESSES}

Declarou não haver.

\section{CONTRIBUIÇÃO DOS AUTORES}

Thiago Paes de Barros De Luccia contribuiu na concepção e desenho deste estudo. Danna Paes de Barros De Luccia participou da análise e interpretação dos dados assim como da redação deste texto.

\section{ENDEREÇO PARA CORRESPONDÊNCIA}

Thiago Paes de Barros De Luccia

Av.São Gualter,346

Vila Ida - São Paulo

CEP 05455-000 SP

E-mail: tpbl@yahoo.com.br 